\title{
"How Should I Think About Voltage? What is Overpotential?": Establishing an Organic Chemistry Intuition for Electrochemistry
}

Jordan E. Nutting, James B. Gerken, Alexios G. Stamoulis, David L. Bruns, Shannon S. Stahl*

Department of Chemistry, University of Wisconsin-Madison, 1101 University Avenue, Madison, Wisconsin 53706, United States

*Corresponding Author: stahl@chem.wisc.edu

Table of Contents

1. Process for Determining Reduction Potentials from Thermochemical Data .................S2

2. Worked Example for the Derivation of the Standard Potential for the Acetone/Isopropanol Redox Couple

3. Process for Determining Molar Entropy from Specific Heat and Temperature Data..S4

4. Tabulated Potentials for the Oxidants...........................................................................6

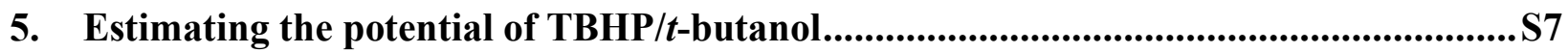

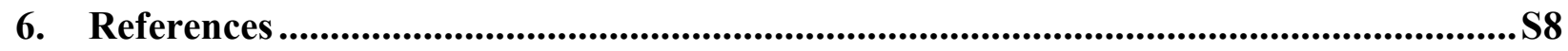




\section{Process for Determining Reduction Potentials from Thermochemical Data}

Reduction potentials were primarily calculated from thermochemical data curated by the National Institute of Standards and Technology (NIST). ${ }^{1}$ Some values were obtained through review of the literature. ${ }^{2-4}$

Below is given the process for determining reduction potentials for a redox couple $A / B$ of the form:

$$
\begin{gathered}
A+n H^{+}+n e^{-} \rightleftharpoons B \\
\text { or } \\
A+n H^{+}+n e^{-} \rightleftharpoons B+m \mathrm{H}_{2} O .
\end{gathered}
$$

First, calculate the standard free energy of formation $\Delta G_{f}^{o}$ of the reactants and products using equation (1):

$$
\Delta G_{f}^{o}(A)=\Delta H_{f}^{o}(A)-T \cdot \Delta S_{f}^{o}(A)
$$

where $\Delta H_{f}^{o}(A)$ is a known, tabulated value and $\Delta S_{f}^{o}(A)$ is calculated from the known, tabulated value for the compound's molar entropy, $S^{o}(A)$, using equation (2):

$$
\Delta S_{f}^{o}(A)=S^{o}(A)-\sum S^{o}\left(C, H_{2}, O_{2}, N_{2}, S, \ldots\right)
$$

where the latter term is the sum of the molar entropies of the constituent elements in their standard states, each normalized for their stoichiometry in the compound of interest. In cases where the molar entropies are not tabulated, they can be extrapolated from known specific heat vs temperature data (vide infra).

Next, calculate the standard free energy of the reaction using equation (3)

$$
\Delta G_{r x n}^{o}=\Delta G_{f}^{o}(B)-\Delta G_{f}^{o}(A)
$$

Finally, calculate the standard potential $E^{o}(\mathrm{~V})$ using equation (4), utilizing the value of $\Delta G_{r x n}^{o}$ $\left(\mathrm{J} \cdot \mathrm{mol}^{-1}\right)$ obtained from equation (3).

$$
E^{o}(v s S H E)=\frac{-\Delta G_{r x n}^{o}}{n \cdot F}
$$




\section{Worked Example for the Derivation of the Standard Potential for the Acetone/Isopropanol Redox Couple}

The balanced equation for the acetone/isopropanol redox couple can be written as follows:

$$
\text { acetone }+2 H^{+}+2 e^{-} \rightleftharpoons \text { isopropanol }
$$

The tabulated thermodynamic values for all relevant species are given in Table S1.. Note that $\Delta H_{f}^{o}$ and $S^{o}$ values were obtained from NIST database, while $\Delta S_{f}^{o}$ and $\Delta G_{f}^{o}$ values were calculated as described above.

Table S1. Thermodynamic values for all species required for standard potential measurements. ${ }^{a}$ Values in italics are exactly zero by definition.

\begin{tabular}{|c|c|c|c|c|}
\hline Species & $\Delta \boldsymbol{H}_{\boldsymbol{f}}^{\mathbf{o}}\left(\mathbf{k J ~ m o l}^{-\mathbf{1}}\right)$ & $\boldsymbol{S}^{\boldsymbol{o}}\left(\mathbf{J ~ m o l}^{-\mathbf{1}} \mathbf{K}^{-\mathbf{1}}\right)$ & $\Delta \boldsymbol{S}_{\boldsymbol{f}}^{\boldsymbol{o}}\left(\mathbf{J ~ m o l}^{-\mathbf{1}} \mathbf{K}^{-\mathbf{1}}\right)$ & $\Delta \boldsymbol{G}_{\boldsymbol{f}}^{\boldsymbol{o}}\left(\mathbf{k J} \mathbf{~ m o l}^{-\mathbf{1}}\right)$ \\
\hline $\mathbf{C}_{(\mathrm{s})}$ & $0^{a}$ & 5.8 & 0 & 0 \\
\hline $\mathbf{H}_{2(\mathrm{~g})}$ & 0 & 130.7 & 0 & 0 \\
\hline $\mathbf{O}_{2(\mathrm{~g})}$ & 0 & 205.2 & 0 & 0 \\
\hline acetone $_{(\mathfrak{)})}$ & -249.4 & 200.4 & -311.7 & -156.5 \\
\hline Isopropanol $_{(\mathfrak{l})}$ & -317.0 & 180.6 & -462.2 & -179.3 \\
\hline
\end{tabular}

First, calculate the standard enthalpy of formation, $\Delta S_{f}^{o}$, for acetone and isopropanol (calculations only shown for acetone). Writing equation (2) for acetone gives:

$$
\Delta S_{f}^{o}(\text { acetone })=S^{o}(\text { acetone })-\left[\left(3 \cdot S_{C}^{o}\right)+\left(3 \cdot S_{H_{2}}^{o}\right)+\left(0.5 \cdot S_{O_{2}}^{o}\right)\right]
$$

Using the tabulated molar entropy values for acetone and its constituent elements in their standard state, the standard entropy of formation can be calculated:

$$
\begin{gathered}
\Delta S_{f}^{o}(\text { acetone })=200.4-[(3 \cdot 5.8)+(3 \cdot 130.7)+(0.5 \cdot 205.2)] \\
\Delta S_{f}^{o}(\text { acetone })=-311.6 \mathrm{~J} \cdot \mathrm{mol}^{-1} \cdot \mathrm{K}^{-1} \\
\Delta S_{f}^{o}(\text { acetone })=-0.3116 \mathrm{~kJ} \cdot \mathrm{mol}^{-1} \cdot \mathrm{K}^{-1}
\end{gathered}
$$

Next, calculate the standard free energy of formation, $\Delta G_{f}^{o}$, for acetone and isopropanol (calculation only shown for acetone).

$$
\begin{gathered}
\Delta G_{f}^{o}(\text { acetone })=\Delta H_{f}^{o}(\text { acetone })-T \cdot \Delta S_{f}^{o}(\text { acetone }) \\
\Delta G_{f}^{o}(\text { acetone })=-249.4-[298 \cdot(-0.3116)] \\
\Delta G_{f}^{o}(\text { acetone })=-156.5 \mathrm{~kJ} \cdot \mathrm{mol}^{-1}
\end{gathered}
$$

Then, calculate the standard free energy of the reaction, $\Delta G_{r x n}^{o}$, for the acetone/isopropanol redox couple using equation (3): 


$$
\begin{gathered}
\Delta G_{r x n}^{o}=\Delta G_{f}^{o}(\text { isopropanol })-\Delta G_{f}^{o}(\text { acetone }) \\
\Delta G_{r x n}^{o}=(-179.3)-(-156.5) \\
\Delta G_{r x n}^{o}=-22.8 \mathrm{~kJ} \cdot \mathrm{mol}^{-1}
\end{gathered}
$$

Finally, Calculate the standard potential for the acetone/isopropanol redox couple using the Nernst equation (4):

$$
\begin{gathered}
E^{o}=\frac{-\Delta G_{r x n}^{o}}{n \cdot F} \\
E^{o}=\frac{-(-22.8)}{2 \cdot 96.485} \\
\boldsymbol{E}^{\boldsymbol{o}}=\mathbf{0 . 1 1 8} \boldsymbol{V} \text { vs } S H E
\end{gathered}
$$

\section{Process for Determining Molar Entropy from Specific Heat and Temperature Data}

In cases where the value for the molar entropy for a compound is not known, it can be estimated from specific heat vs. temperature data, should the latter also be available. This can be done by using the relationship between entropy and specific heat capacity, $C_{p}$ :

$$
T d S=C_{p} d T
$$

Equation (5) can be used to find an expression for the change in entropy over a given temperature range:

$$
\begin{gathered}
d S=\frac{C_{p}}{T} d T \\
\int d S=\int_{T_{1}}^{T_{2}} \frac{C_{p}}{T} d T \\
\Delta S=\int_{T_{1}}^{T_{2}} \frac{C_{p}}{T} d T
\end{gathered}
$$

Using an empirical polynomial fit of the heat capacity, we can rewrite the above equation:

$$
\Delta S=\int_{T_{1}}^{T_{2}} \frac{\left(A T^{3}+B T^{2}+C T+D\right)}{T} d T=\int_{T_{1}}^{T_{2}}\left(A T^{2}+B T+C+D T^{-1}\right) d T
$$

The definite integral can be expressed as:

$$
\Delta S=\int_{T_{1}}^{T_{2}}\left(A T^{2}+B T+C+D T^{-1}\right) d T=\left[\frac{A T^{3}}{3}+\frac{B T^{2}}{2}+C T+D \ln (T)+E\right]_{T 1}^{T 2}
$$




$$
\begin{gathered}
\Delta S=\left[\frac{A T_{2}^{3}}{3}+\frac{B T_{2}^{2}}{2}+C T_{2}+D \ln \left(T_{2}\right)+E\right]-\left[\frac{A T_{1}^{3}}{3}+\frac{B T_{1}^{2}}{2}+C T_{1}+D \ln \left(T_{1}\right)+E\right] \\
\Delta S=\frac{A}{3}\left(T_{2}^{3}-T_{1}^{3}\right)+\frac{B}{2}\left(T_{2}^{2}-T_{1}^{2}\right)+C\left(T_{2}-T_{1}\right)+D \ln \left(\frac{T_{2}}{T_{1}}\right)
\end{gathered}
$$

Therefore, specific heat vs. temperature data can be fit using a cubic polynomial function, which can give values for the parameters $A, B, C$, and $D$. Using the Debye theory assumption that in the low temperature limit, $C_{p}=A_{D} T^{3}$, we select a temperature of $10 \mathrm{~K}$ as the point where the two $C_{p}$ models cross over. From this, the value of $A_{D}$ and $\Delta S$ from $T_{1}=0 \mathrm{~K}$ (absolute zero) to $T_{2}=10 \mathrm{~K}$ are determined. Subsequently, the molar change in entropy, $\Delta S$, from $T_{1}=10 \mathrm{~K}$ to $T_{2}=298 \mathrm{~K}$ can be calculated using equation (6). Notice that the overall molar change in entropy from absolute zero to $298 \mathrm{~K}$ is equal to the standard molar entropy of the compound (i.e., in this specific case, $\Delta S=S^{o}$ ) minus the entropy of any phase changes.

Table S2. Specific heat vs temperature data for isopropanol

\begin{tabular}{|c|c|}
\hline $\boldsymbol{C}_{\boldsymbol{p}}\left(\mathrm{J} \mathrm{mol}^{-1} \mathrm{~K}^{-1}\right)$ & $\boldsymbol{T}(\mathrm{K})$ \\
\hline 35.32 & 50 \\
\hline 46.04 & 100 \\
\hline 57.98 & 150 \\
\hline 68.28 & 200 \\
\hline 83.72 & 273.15 \\
\hline 89.32 & 298.15 \\
\hline
\end{tabular}

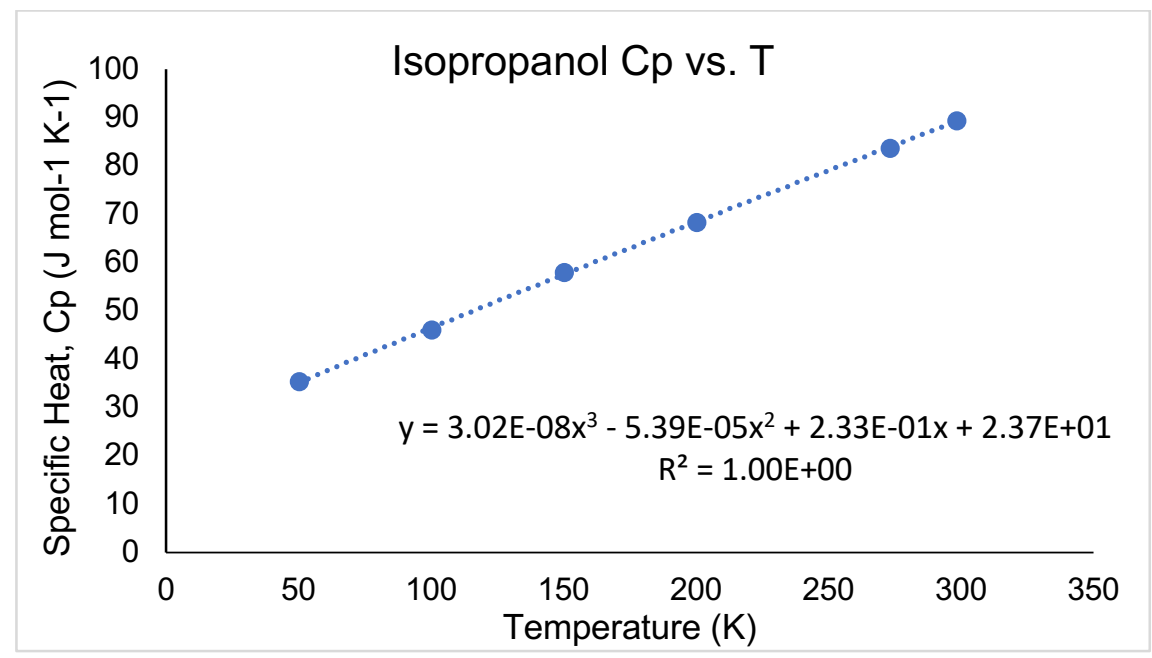

Figure S1. Specific heat vs temperature data for isopropanol with cubic line of best fit.

The line of best fit from Figure S1. gives values for $A, B, C$, and $D$ of $3.0 \cdot 10^{-8},-5.4 \cdot 10^{-5}$, $2.3 \cdot 10^{-1}$, and 23.7 , respectively. The $\mathrm{C}_{\mathrm{p}}$ at $\mathrm{T}=10 \mathrm{~K}$ is determined using equation (6) and the 
values for $A, B, C$, and $D$, giving a value of $26 \mathrm{~J} \cdot \mathrm{mol}^{-1} \cdot \mathrm{K}^{-1}$. The value for $\mathrm{A}_{\mathrm{D}}$ at $\mathrm{T}=10 \mathrm{~K}$ is subsequently evaluated to be 0.026 . The definite integral of $\mathrm{C}_{\mathrm{p}}=\mathrm{A}_{\mathrm{D}} \mathrm{T}^{3}$ from $T_{1}=0 \mathrm{~K}$ to $T_{2}=$ $10 \mathrm{~K}$ gives a corresponding low-temperature entropy of $8.7 \mathrm{~J} \cdot \mathrm{mol}^{-1} \cdot \mathrm{K}^{-1}$. The molar change in entropy, $\Delta S$, from $T_{1}=10 \mathrm{~K}$ to $T_{2}=298 \mathrm{~K}$ calculated using equation (6) is $145 \mathrm{~J} \cdot \mathrm{mol}^{-1} \cdot \mathrm{K}^{-1}$. The value for $S^{o}$ obtained after summing the above two values and adding the entropy of fusion $\left(29.2 \mathrm{~J} \cdot \mathrm{mol}^{-1} \cdot \mathrm{K}^{-1}\right)$ is $183 \mathrm{~J} \cdot \mathrm{mol}^{-1} \cdot \mathrm{K}^{-1}$. This is in close agreement with the literature molar entropy value of $181 \mathrm{~J} \cdot \mathrm{mol}^{-1} \cdot \mathrm{K}^{-1}$ for isopropanol. The standard potential values for the acetone/isopropanol couple obtained using the estimated and literature molar entropy values of isopropanol are $0.122 \mathrm{~V}$ and $0.118 \mathrm{~V}$ vs SHE, respectively. The difference of $4 \mathrm{mV}$ is small compared to the difference in substrate/mediator or substrate/oxidant potentials, validating this method as a way of estimating molar entropy values. This approach was used to derive $S^{o}$ for acetanilide.

\section{Tabulated Potentials for the Oxidants}

The potentials of the oxidants listed in Figure 2 are collected with the associated references in 5-10

Table S3. Potentials (vs. SHE) for the oxidant half reactions listed in Figure 1. TBHP = tert-Butyl hydroperoxide; $\mathrm{TEMPO}^{+}=$2,2,6,6-tetramethyl-1-oxopiperidinium; $\mathrm{TEMPOH}_{2}^{+}=2,2,6,6$ tetramethyl-1-hydroxyl piperidinium; DDQ $=$ 2,3-dichloro-5,6-dicyano-1,4-benzoquinone; $\mathrm{DDH}_{2} \mathrm{Q}=$ 2,3-dichloro-5,6-dicyano-1,4-hydroquinone; $\mathrm{BQ}=1$,4-benzoquionone; $\mathrm{H}_{2} \mathrm{Q}=1$,4hydroquinone. ${ }^{a}$ Potential vs. NHE.

\begin{tabular}{|c|c|c|}
\hline Oxidant Reactions & $\Delta \mathbf{E}^{\circ}(\mathrm{V})$ & Reference \\
\hline $\mathrm{O}_{2}+4 \mathrm{H}^{+}+4 e^{-} \rightleftharpoons \mathrm{H}_{2} \mathrm{O}$ & 1.23 & (7) \\
\hline $\mathrm{O}_{2}+2 \mathrm{H}^{+}+2 e^{-} \rightleftharpoons \mathrm{H}_{2} \mathrm{O}_{2}$ & 0.68 & \\
\hline $\mathrm{H}_{2} \mathrm{O}_{2}+2 \mathrm{H}^{+}+2 e^{-} \rightleftharpoons 2 \mathrm{H}_{2} \mathrm{O}$ & 1.78 & (7) \\
\hline $\mathrm{O}_{3}+2 \mathrm{H}^{+}+2 e^{-} \rightleftharpoons \mathrm{O}_{2}+\mathrm{H}_{2} \mathrm{O}$ & 2.08 & $(7)$ \\
\hline $\mathrm{S}_{2} \mathrm{O}_{8}^{-2}+2 \mathrm{H}^{+}+2 e^{-} \rightleftharpoons 2 \mathrm{SO}_{4}^{-2}$ & 2.01 & (7) \\
\hline $\mathrm{TBHP}+2 \mathrm{H}^{+}+2 e^{-} \rightleftharpoons t \mathrm{BuOH}+\mathrm{H}_{2} \mathrm{O}$ & $\sim 1.7$ & (see below) \\
\hline $\mathrm{MnO}_{4}^{-}+8 \mathrm{H}^{+}+5 e^{-} \rightleftharpoons \mathrm{Mn}^{+2}+4 \mathrm{H}_{2} \mathrm{O}$ & 1.507 & $(7)$ \\
\hline$P h I X_{2}+2 e^{-} \rightleftharpoons P h I+2 X^{-}$ & $\sim 1.35^{a}$ & $(5),(6)$ \\
\hline $\mathrm{Cr}_{2} \mathrm{O}_{7}^{-2}+14 \mathrm{H}^{+}+6 e^{-} \rightleftharpoons 2 \mathrm{Cr}^{+3}+7 \mathrm{H}_{2} \mathrm{O}$ & 1.36 & $(7)$ \\
\hline$B r_{2(a q)}+2 e^{-} \rightleftharpoons 2 B r^{-}$ & 1.09 & (7) \\
\hline $\mathrm{NO}_{2}+2 \mathrm{H}^{+}+2 e^{-} \rightleftharpoons \mathrm{NO}+\mathrm{H}_{2} \mathrm{O}$ & 1.05 & $(8)$ \\
\hline $\mathrm{TEMPO}^{+}+2 \mathrm{H}^{+}+2 e^{-} \rightleftharpoons \mathrm{TEMPOH}{ }_{2}^{+}$ & $0.91^{a}$ & $(9)$ \\
\hline$D D Q+2 H^{+}+2 e^{-} \rightleftharpoons D D H_{2} Q$ & $0.89^{a}$ & $(10)$ \\
\hline$B Q+2 H^{+}+2 e^{-} \rightleftharpoons H_{2} Q$ & $0.64^{a}$ & $(10)$ \\
\hline$I_{2}+2 e^{-} \rightleftharpoons 2 I^{-}$ & 0.54 & $(7)$ \\
\hline
\end{tabular}




\section{Estimating the potential of $\mathrm{TBHP} / \mathrm{t}$-butanol}

Though the $\Delta H_{f}^{o}$ of tert-butyl hydroperoxide (TBHP) is tabulated, ${ }^{1}$ the molar entropy $S^{o}$ is not known, nor is heat capacity vs temperature data for this compound available. Therefore, estimating $S^{o}$ for TBHP as described above is not feasible. To approximate this value, an assumption can be made that the $\Delta S_{r x n}^{o}$ for the TBHP/t $\mathrm{BuOH}+\mathrm{H}_{2} \mathrm{O}$ couple is the same as that for the $\mathrm{H}_{2} \mathrm{O}_{2} / \mathrm{H}_{2} \mathrm{O}$ couple. This is a reasonable assumption, since, barring any dramatic solvation effects, the difference in entropy for the two redox couples should be dictated by the $1: 2$ stoichiometry of sub ${ }^{\text {ox }}$ : sub ${ }^{\text {red }}$, as well as the degrees of freedom gained/lost upon replacing an $\mathrm{O}-\mathrm{O}$ bond with two $\mathrm{O}-\mathrm{H}$ bonds.

We can write a balanced redox couple for $\mathrm{H}_{2} \mathrm{O}_{2} / \mathrm{H}_{2} \mathrm{O}$ and write the corresponding expression for the standard free energy of the reaction:

$$
\begin{gathered}
\mathrm{H}_{2} \mathrm{O}_{2}+2 \mathrm{H}^{+}+2 e^{-} \rightleftharpoons 2 \mathrm{H}_{2} \mathrm{O} \\
\Delta G_{r x n}^{o}=2 \cdot \Delta G_{f}^{o}\left(\mathrm{H}_{2} \mathrm{O}\right)-\Delta G_{f}^{o}\left(\mathrm{H}_{2} \mathrm{O}_{2}\right) \\
\Delta G_{r x n}^{o}=2 \cdot\left[\Delta H_{f}^{o}\left(\mathrm{H}_{2} \mathrm{O}\right)-T \cdot \Delta S_{f}^{o}\left(\mathrm{H}_{2} \mathrm{O}\right)\right]-\left[\Delta H_{f}^{o}\left(\mathrm{H}_{2} \mathrm{O}_{2}\right)-T \cdot \Delta S_{f}^{o}\left(\mathrm{H}_{2} \mathrm{O}_{2}\right)\right] \\
\Delta G_{r x n}^{o}=\left[2 \cdot \Delta H_{f}^{o}\left(\mathrm{H}_{2} \mathrm{O}\right)-\Delta H_{f}^{o}\left(\mathrm{H}_{2} \mathrm{O}_{2}\right)\right]+T \cdot\left[\Delta S_{f}^{o}\left(\mathrm{H}_{2} \mathrm{O}_{2}\right)-2 \cdot \Delta S_{f}^{o}\left(\mathrm{H}_{2} \mathrm{O}\right)\right]
\end{gathered}
$$

The standard change in entropy for the $\mathrm{H}_{2} \mathrm{O}_{2} / \mathrm{H}_{2} \mathrm{O}$ redox couple can be expressed as:

$$
\Delta S_{r x n}^{o}\left(H_{2} \mathrm{O}_{2} / \mathrm{H}_{2} \mathrm{O}\right)=\Delta S_{f}^{o}\left(\mathrm{H}_{2} \mathrm{O}_{2}\right)-2 \cdot \Delta S_{f}^{o}\left(\mathrm{H}_{2} \mathrm{O}\right)
$$

Similarly, we can write a balanced redox couple for $\mathrm{TBHP} / \mathrm{BuOH}+\mathrm{H}_{2} \mathrm{O}$ and write the corresponding expression for the standard free energy of the reaction:

$$
\begin{gathered}
T B H P+2 H^{+}+2 e^{-} \rightleftharpoons t B u O H+H_{2} O \\
\Delta G_{r x n}^{o}=\Delta G_{f}^{o}\left(H_{2} O\right)+\Delta G_{f}^{o}(t B u O H)-\Delta G_{f}^{o}(T B H P) \\
\Delta G_{r x n}^{o}=\left[\Delta H_{f}^{o}\left(H_{2} O\right)-T \cdot \Delta S_{f}^{o}\left(H_{2} O\right)\right]+\left[\Delta H_{f}^{o}(t B u O H)-T \cdot \Delta S_{f}^{o}(t B u O H)\right] \\
-\left[\Delta H_{f}^{o}(T B H P)-T \cdot \Delta S_{f}^{o}(T B H P)\right] \\
\Delta G_{r x n}^{o}=\left[\Delta H_{f}^{o}\left(H_{2} O\right)+\Delta H_{f}^{o}(t B u O H)-\Delta H_{f}^{o}(T B H P)\right]+T \cdot\left[\Delta S_{f}^{o}(T B H P)\right. \\
\left.-\Delta S_{f}^{o}\left(H_{2} O\right)-\Delta S_{f}^{o}(t B u O H)\right]
\end{gathered}
$$

The standard change in entropy for the TBHP/tBuOH redox couple can be expressed as:

$$
\Delta S_{r x n}^{o}(T B H P / t B u O H)=\Delta S_{f}^{o}(T B H P)-\Delta S_{f}^{o}\left(H_{2} O\right)-\Delta S_{f}^{o}(t B u O H)
$$

Based on our assumption that $\Delta S_{r x n}^{o}$ for the TBHP $/ t \mathrm{BuOH}+\mathrm{H}_{2} \mathrm{O}$ couple is the same as that for the $\mathrm{H}_{2} \mathrm{O}_{2} / \mathrm{H}_{2} \mathrm{O}$ couple (using the value for liquid phase $\mathrm{H}_{2} \mathrm{O}_{2}$ ), we can write: 


$$
\Delta S_{r x n}^{o}(T B H P / t B u O H)=\Delta S_{r x n}^{o}\left(H_{2} O_{2} / H_{2} O\right)=\Delta S_{f}^{o}\left(H_{2} O_{2}\right)-2 \cdot \Delta S_{f}^{o}\left(H_{2} O\right)
$$

Thus, the expression for the standard free energy of the TBHP/tBuOH$+\mathrm{H}_{2} \mathrm{O}$ redox couple becomes:

$$
\begin{gathered}
\Delta G_{r x n}^{o}=\left[\Delta H_{f}^{o}\left(H_{2} O\right)+\Delta H_{f}^{o}(t B u O H)-\Delta H_{f}^{o}(T B H P)\right]+T \cdot\left[\Delta S_{f}^{o}\left(H_{2} O_{2}\right)-2\right. \\
\left.\cdot \Delta S_{f}^{o}\left(H_{2} O\right)\right]
\end{gathered}
$$

The above free energy is now expressed in terms of known or calculable values. ${ }^{1,4}$ Inserting the above values gives:

$$
\begin{gathered}
\Delta G_{r x n}^{o}=\left[\left(-285.83 \mathrm{~kJ} \cdot \mathrm{mol}^{-1}\right)+\left(-359.2 \mathrm{~kJ}^{\prime} \cdot \mathrm{mol}^{-1}\right)-\left(-294 \mathrm{~kJ} \cdot \mathrm{mol}^{-1}\right)\right] \\
+298 \mathrm{~K} \cdot\left[\left(-0.22636 \mathrm{~kJ} \cdot \mathrm{mol}^{-1} \cdot \mathrm{K}^{-1}\right)-2 \cdot(-0.163305 \mathrm{~kJ}\right. \\
\left.\left.\cdot \mathrm{mol}^{-1} \cdot \mathrm{K}^{-1}\right)\right] \\
\Delta G_{r x n}^{o}=-321.16 \mathrm{~kJ} \mathrm{~mol}^{-1}
\end{gathered}
$$

Using the Nernst equation for the $2 \mathrm{e}^{-} / 2 \mathrm{H}^{+}$couple, the expression for the standard potential becomes:

$$
\begin{gathered}
E^{o}=\frac{-\Delta G_{r x n}^{o}}{n \cdot F} \\
E^{o} \sim \frac{-(-321.16) * 1000}{2 \cdot 96.485} \\
\boldsymbol{E}^{\text {oo }} \sim \mathbf{7} \boldsymbol{V} \text { vs } S H E
\end{gathered}
$$

\section{References}

1. NIST Chemistry WebBook, NIST Standard Reference Database Number 69, P. J. Linstrom and Mallard, W. G., Eds.; National Institutes of Standards and Technology, Gaithersburg MD, 20899, https://webbook.nist.gov/chemistry/.

2. Domalski, E. S.; Hearing, E. D. Estimation of the Thermodynamic Properties of Hydrocarbons at 298.15 K. J. Phys. Chem. Ref. Data 1988, 17, 1637-1678.

3. Careri, G.; Buontempo, U.; Galluzi, F.; Scott, A. C.; Gratton, E.; Shyamsunder, E. Spectroscopic Evidence for Davydov-like Solitons in Acetanilide. Phys. Rev. B. 1984, 30, 4689-4702.

4. Giguère, P. A.; Liu, I. D.; Dugdale, J. S.; Morrison, J. A. Hydrogen Peroxide: The Low Temperature Heat Capacity of the Solid and the Third Law Entropy. Can. J. Chem. 1954, 32, $117-128$.

5. Kokkinidis, G.; Hatzigrigoriou, E.; Sazou, D.; Varvoglis, A. Electrochemical Reduction of Some Hypervalent Iodine Compounds. Electrochim. Acta 1991, 36, 1391-1395.

6. Devadas, B.; Svoboda, J.; Krupička, M.; Bystron, T. Electrochemical and Spectroscopic Study of 2-Iodobenzoic Acid and 2-Iodosobenzoic Acid Anodic Oxidation in Aqueous Environment. Electrochim. Acta 2020, 342, 1-11.

7. CRC Handbook of Chemistry and Physics $101^{\text {st }}$ Edition, J Rumble, Ed.; CRC Press, Cleveland, OH, 2020. https://hbcp.chemnetbase.com/faces/contents/ContentsSearch.xhtml 
8. Gerken, J. B.; Stahl, S. S. High-Potential Electrocatalytic $\mathrm{O}_{2}$ Reduction with Nitroxyl/ $\mathrm{NO}_{\mathrm{x}}$ Mediators: Implications for Fuel Cells and Aerobic Oxidation Catalysis. ACS Cent. Sci. 2015, 1, 234-243.

9. Gerken, J. B.; Pang, Y. Q.; Lauber, M. B.; Stahl, S. S. Structural Effects on the pHDependent Redox Properties of Organic Nitroxyls: Pourbaix Diagram for TEMPO, ABNO, and Three TEMPO Analogs. J. Org. Chem. 2018, 83, 7323-7330.

10. Huynh, M. T.; Anson, C. W.; Cavell, A. C.; Stahl, S. S.; Hammes-Schiffer, S. Quinone 1e ${ }^{-}$ and $2 \mathrm{e}^{-} / 2 \mathrm{H}^{+}$Reduction Potentials: Identification and Analysis of Deviations from Systematic Scaling Relationships. J. Am. Chem. Soc. 2016, 138, 15903-15910. 